\title{
GLUCOSE HOMEOSTASIS ALTERATIONS IN CUSHING'S DISEASE: EPIDEMIOLOGY, ANTHROPOMETRIC ASSESSMENT AND THE ROLE OF FAMILY HISTORY OF TYPE 2 DIABETES.
}

\section{Przemysław Witek¹, Joanna Witek²,3, Grzegorz Zieliński³, Marlena Błazik², Grzegorz Kamiński1 \\ 1 Department of Endocrinology and Isotope Therapy, Military Institute of Medicine, Warsaw, POLAND \\ 2 Outpatient Clinic, Institute of the Mother and Child, Warsaw, POLAND ${ }^{3}$ Department of Neurosurgery, Military Institute of Medicine, Warsaw, POLAND}

\section{INTRODUCTION:}

Cushing's disease $(C D)$ leads to glucose homeostasis alterations, obesity, unfavorable changes in body composition and cardiovascular complications.

AIM OF THE STUDY:

1. Prospective evaluation of the frequency of pre-diabetes and diabetes. 2. Assessment of insulin resistance (IR) indices in CD. 3. Analysis of the influence of family history of type 2 diabetes (T2D) on the anthropometry in CD.

\section{METHODS:}

The study group included 47 patients with CD (37 women and 10 men aged $43.1 \pm 14.6)$. Waist and hip circumferences, body mass index(BMI) and body fat content were recorded. Glucose and insulin levels during an oral glucose tolerance test(OGTT) were assessed. HOMA-IR, QUICKI and Matsuda indices were calculated. Patients previously diagnosed with diabetes were examined exclusively for fasting glucose and $\mathrm{HbA} 1 \mathrm{c}$.

\section{RESULTS:}

Sixteen patients $(34 \%)$ had diabetes, another $18(38.3 \%)$ had pre-diabetes. Hypertension was confirmed in 37 patients $(78.7 \%)$. Mean total fat content was $34.52 \pm 10.64 \mathrm{~kg}$; trunk fat was $17.49 \pm 5$. $18 \mathrm{~kg}$. Mean BMI was $30.9 \pm 6.6 \mathrm{~kg} / \mathrm{m}^{2}$. Obesity was confirmed in 23 patients $(48,9 \%)$ and overweight in $17(36.2 \%)$. In patients with hypertension trunk fat was higher than in the normotensive group $(18.38 \pm 4.87 \mathrm{~kg}$ vs. $14.25 \pm 5.2 \mathrm{~kg}, \mathrm{p}<0.05)$. Positive family history of T2D was found in 15 patients $(32 \%)$. It was associated with a greater hip circumference $(114.37 \pm 17.84 \mathrm{~cm}$ vs. $102.81 \pm 9.6 \mathrm{~cm}, \mathrm{p}<0.05)$ compared to those without T2D in the family history. Matsuda and QUICKI indices were higher in patients without concomitant glucose homeostasis alterations than in patients with pre-diabetes $(4.01 \pm 2.04$ vs $2.08 \pm 0.92, p=0.001$ and $0.338 \pm 0.034$ vs. $0.311 \pm 0.024, p=0.01$, respectively). There was no significant difference with regards to HOMA-IR $(2.78 \pm 1.44$ vs.5.33 \pm 4.82 , $\mathrm{p}=0.08$ ).

Table 1. IR-indices in patients with pre-diabetes and normal glucose tolerance

\begin{tabular}{|c|c|c|c|}
\hline & MATSUDA & QUICKI & HOMA-IR \\
\hline Pre-diabetes & $2.08 \pm 0.92$ & $0.311 \pm 0.024$ & $5.33 \pm 4.82$ \\
\hline Normal glucose tolerance & $4.01 \pm 2.04$ & $0.338 \pm 0.034$ & $2.78 \pm 1.44$ \\
\hline$p$ & $\mathbf{0 . 0 0 1}$ & $\mathbf{0 . 0 1}$ & 0.08 \\
\hline
\end{tabular}

Figure 1. Frequency of metabolic complications in Cushing's disease

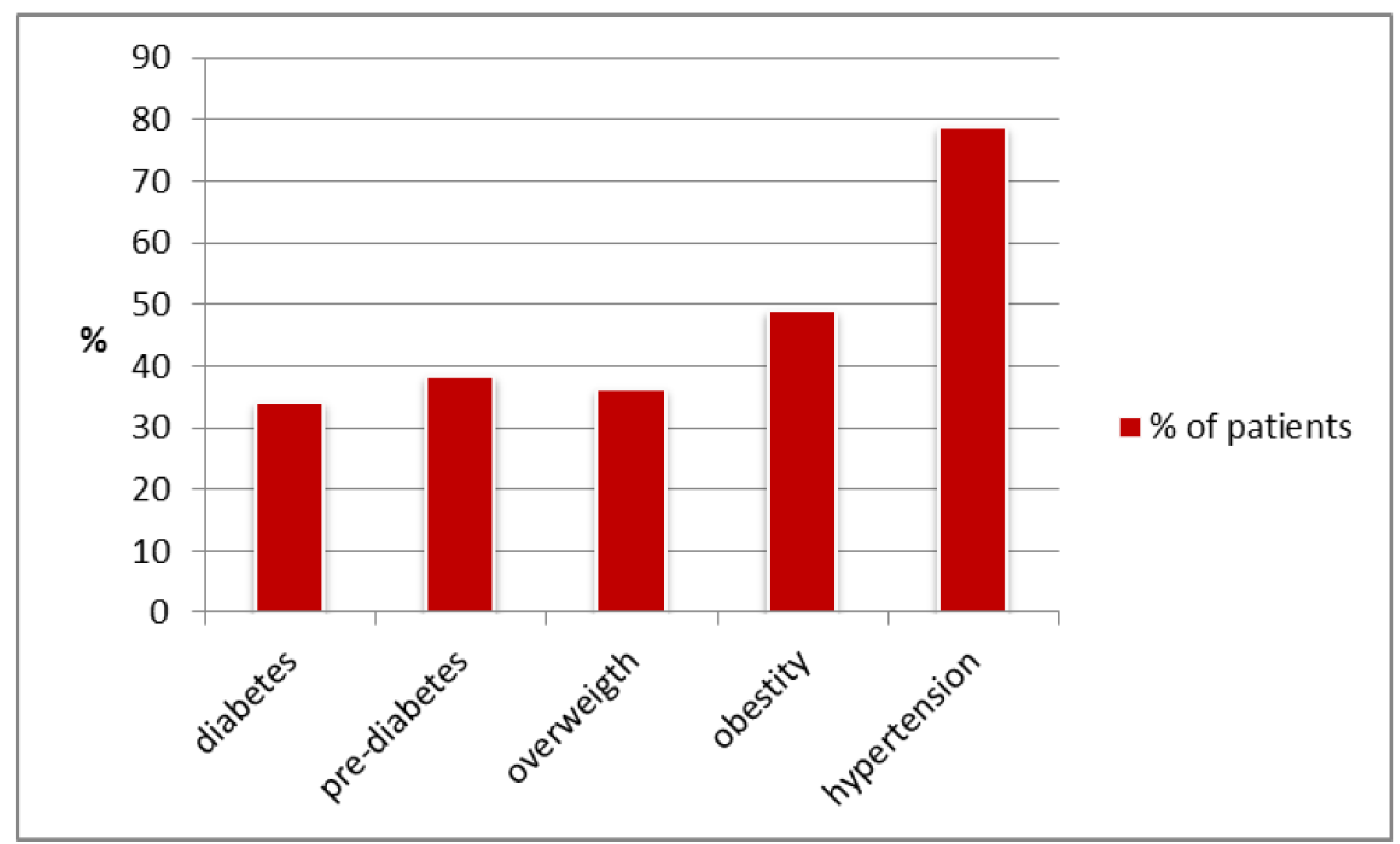

\section{CONCLUSIONS}

1.Glucose homeostasis alterations were observed in $70 \%$ of patients with $C D$. 2. We confirmed the association between the presence of arterial hypertension and trunk fat content. 3. The family history of T2D may be associated with a higher risk of obesity in CD. 4.Matsuda index contrary to HOMA-IR may be a more sensitive marker of IR in CD. 